\title{
Tuberculin testing in residential homes for the elderly
}

\author{
M Nisar, C S D Williams, D Ashby, P D O Davies
}

\begin{abstract}
Background-Evidence from the United States has shown that tuberculin sensitivity increases with length of stay among residents in homes for the elderly, implying an increasing risk of infection. There is no evidence as to whether or not residents in homes in the United Kingdom have a similar risk.

Methods-A study was undertaken to determine whether residence in a home for the elderly increases the risk of tuberculosis infection. Over a six month period all residents in homes for the elderly in Liverpool received a tuberculin test. A health questionnaire was completed by the field team for each resident. A total of 2665 residents in homes for the elderly were surveyed.
\end{abstract}

Results-Heaf test grade positivity declined with age, the odds ratio being 0.71 for each 10 year period. Adjusting for age, there was no change in Heaf test grade with length of stay in the home. Heaf test positivity was stronger in smokers (odds ratio 1.59) than exsmokers (odds ratio 1.20) and non-smokers. Heaf test grade positivity was directly related to pack years. Allowing for age and smoking, the odds ratio for men compared with women for a positive test was $1.62(95 \%$ confidence interval $1 \cdot 32$ to $1 \cdot 99$ ).

Conclusions-Heaf test positivity declines with age. Residence in a home for the elderly is not associated with increased rate of tuberculosis sensitivity. Smoking and male gender is associated with increased Heaf test positivity.

(Thorax 1993;48:1257-1260)

Globally, tuberculosis is increasing. In England and Wales a 9\% annual decline from 1980 to 1985 has reverted to a $2 \%$ annual increase from 1987. The biggest single group causing such a rise is the elderly. In the indigenous white population rates of tuberculosis are highest in the elderly, particularly elderly men. ${ }^{1}$ Between 1987 and 1989 numbers of cases in men aged 75 or over increased by $15 \% .^{2}$

In the UK an increasing proportion of elderly are now accommodated in residential and nursing homes. ${ }^{3}$ Evidence from the USA suggests that residents in homes for the elderly are at increased risk of incurring tuberculosis infection and disease compared with those remaining in the community. In residents of such homes it has been shown that length of stay in the homes is associated with an increasing likelihood of a positive tuberculin test. ${ }^{4}$ The proportion of 80 year olds with tuberculosis was found to be very much higher in residential homes than in those living in the community. ${ }^{5}$ There have also been outbreaks of tuberculosis within these homes where a single index case resulted in many cases of secondary disease. ${ }^{6}$ An individual who has reactivation of tuberculosis infection can be highly infectious and can infect other residents. Because of the close proximity in which people live in such homes, disease can spread rapidly. Reduced immunity in old age is also likely to aggravate the rapid spread of infection. It is therefore possible that, by bringing together many elderly people under one roof, increased spread of infection may be occurring in the UK as has been reported from the USA. If this is so, suitable screening and regular follow up may be required amongst residents of such homes to prevent possible outbreaks of tuberculosis. These preventive measures are particularly important as tuberculosis in the elderly not only may present atypically, ${ }^{7}$ but may also be associated with rapid progression and high mortality. ${ }^{8}$

To date there is little evidence that the risk of tuberculosis increases with the length of stay in residential homes for the elderly in the UK, although it has been well established to be a risk factor for alcoholics and those of no fixed abode. ${ }^{910}$ To investigate whether the American experience is repeated in the $\mathrm{UK}$, we have undertaken a study of tuberculosis infection by tuberculin testing among residents of nursing and residential homes in Liverpool.

\section{Methods}

Between January and June 1990 all nursing homes and residential homes for the elderly in Liverpool were visited (by $\mathrm{MN}$ and CSDW) after prior consultation by letter or telephone with the person in charge of each home. All residents were Heaf tested by standard methods. ${ }^{11} \mathrm{~A}$ questionnaire on each resident was completed by the visiting team, often with the help of staff of the homes if this 
Table 1 Age and sex distribution of subjects in study

\begin{tabular}{lcccccccc}
\hline \multicolumn{7}{l}{ Age (years) } & & \\
\cline { 2 - 7 } & $<45$ & $45-54$ & $55-64$ & $65-74$ & $75-84$ & $85-94$ & $95-104$ & Total \\
\hline Men & 5 & 5 & 43 & 165 & 284 & 157 & 10 & 669 \\
Women & 6 & 12 & 42 & 218 & 796 & 815 & 103 & 1992 \\
Total & 11 & 17 & 85 & 383 & 1080 & 972 & 113 & $2661^{\star}$ \\
\hline
\end{tabular}

$\star$ Data on age was not available for four patients.

Table 2 Relation between Heaf grade and gender

\begin{tabular}{|c|c|c|c|c|c|c|}
\hline & \multicolumn{5}{|c|}{ Heaf grade } & \multirow[b]{2}{*}{ Total } \\
\hline & 0 & 1 & 2 & 3 & 4 & \\
\hline Men & $\begin{array}{l}398 \\
(60)\end{array}$ & $\begin{array}{l}88 \\
(13)\end{array}$ & $\begin{array}{l}96 \\
(14)\end{array}$ & $\begin{array}{l}52 \\
(8)\end{array}$ & $\begin{array}{l}29 \\
(4)\end{array}$ & $\begin{array}{l}663 \\
(100)\end{array}$ \\
\hline Women & $\begin{array}{l}1506 \\
(76)\end{array}$ & $\begin{array}{l}209 \\
(11)\end{array}$ & $\begin{array}{l}142 \\
(7)\end{array}$ & $\begin{array}{l}81 \\
(4)\end{array}$ & $\begin{array}{l}34 \\
(2)\end{array}$ & $\begin{array}{l}1972 \\
(100)\end{array}$ \\
\hline Total & $\begin{array}{l}1904 \\
(72 \cdot 3)\end{array}$ & $\begin{array}{l}297 \\
(11 \cdot 3)\end{array}$ & $\begin{array}{l}238 \\
(9 \cdot 0)\end{array}$ & $\begin{array}{l}133 \\
(5 \cdot 0)\end{array}$ & $\begin{array}{l}63 \\
(2 \cdot 4)\end{array}$ & $\begin{array}{l}2635 \\
(100)\end{array}$ \\
\hline
\end{tabular}

Values in parentheses are percentages.

was required. Details in the questionnaire included: demographic data, details on immunosuppressive medication (including steroids), whether the resident had previously had tuberculosis or treatment for tuberculosis, smoking status and, in ex-smokers and current smokers, the number of pack years smoked. The presence or absence of a cough, its productivity, and the residents' own assessment of general well being were included. An assessment of the general mental state of the resident was made, often with the assistance of a member of staff. Further details included the number of residents in the home, and the number of weeks the resident had been present in the home. Each home was revisited after one week (CSDW) to read and record the Heaf grade of all residents.

Heaf test grading was as follows: 1 -at

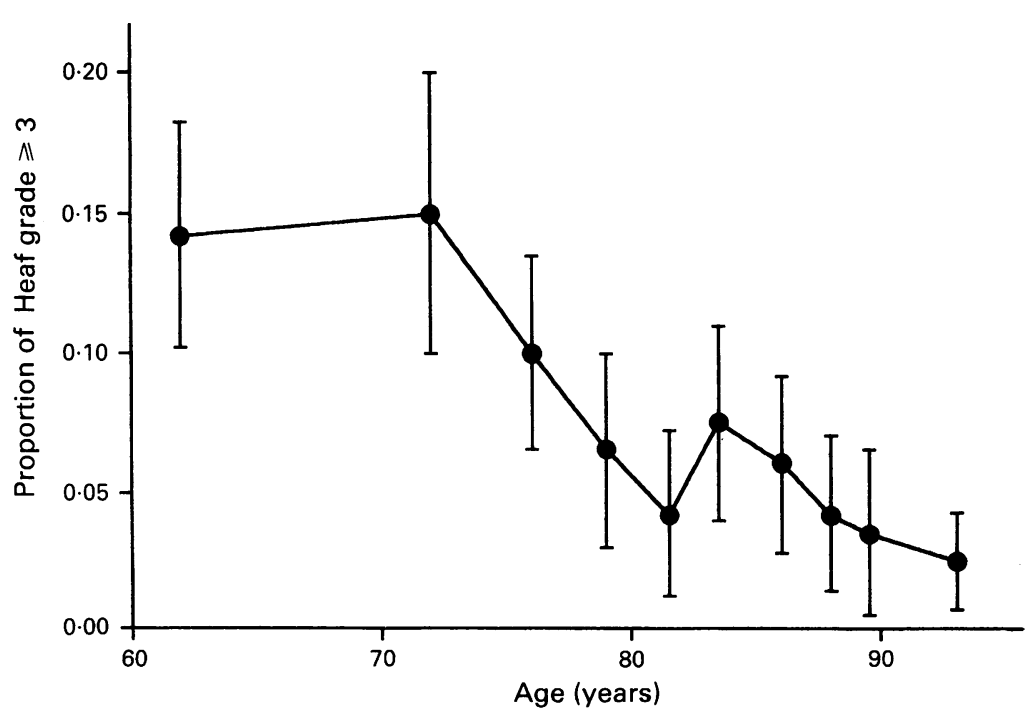

Figure 1 Relation between Heaf grade and age. Residents were divided into 10 numerically equal groups. The point chosen represents the mean age of that group and the proportion with Heaf grade $\geqslant 3$. Vertical lines give $95 \%$ confidence intervals. (For statistical explanation see text). least four separate papules; $2-$ a continuous ring of induration; $3-\mathrm{a}$ closed ring up to $10 \mathrm{~mm} ; 4-$ a closed ring greater than $10 \mathrm{~mm}$ or with vesicles present.

Ethical approval was obtained from the appropriate ethical committees of Liverpool and South Sefton district health authorities.

Each resident signed a consent form agreeing to be Heaf tested and questioned.

\section{STATISTICAL ANALYSIS}

Simple descriptive statistics were used and are presented. Ordered logistic regression models $^{12}{ }^{13}$ were used to determine the effect of different variables (age, sex, length of stay in homes) on the Heaf test results. This assumes that, whatever Heaf grade cutoff has been considered, the variables in the model and their coefficients should remain the same. Odds ratios for the probabilities of having a $\vec{\infty}$ Heaf grade above any given cutoff can be $\vec{N}$ obtained for covariables of interest from the relevant regression coefficients. Odds ratios are approximately equal to relative risks for rare events, such as having a strong Heaf reaction. Analyses were carried out using the statistical packages SAS for data manipulation, tabulations, and analysis. ${ }^{14} 15$

Residents were divided into 10 numerically equal groups. The points shown in the figures represent the mean age of that group and the proportion with Heaf grade $\geqslant 3$.

\section{Results}

A total of 2665 residents ( $75 \%$ women) were tested and a questionnaire completed in 88 homes. The median number per home was 40 , range $11-120$, and the median length of stay was 78 weeks. The median age of the residents was 83 years, range 22-104 (table 1). Ninety one (3.4\%) had had previous treatment for tuberculosis. No statistically significant difference in Heaf test result was found between these residents and those who had not had previous treatment.

Heaf test results were available for 2635 residents and are shown in table 2 . The Heaf $\mathrm{O}$ test result was grade 0 in $1904(72.3 \%)$, grade 1 in $297(11.3 \%)$, grade 2 in 238

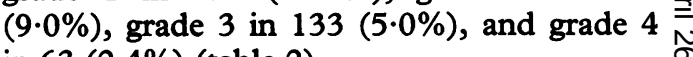
in $63(2 \cdot 4 \%)$ (table 2 ).

A total of $1379(51.8 \%)$ had never N smoked, $840(31.0 \%)$ were ex-smokers, and $\underset{\omega}{N}$ $443(16.6 \%)$ were current smokers. The smoking history was uncertain in three cases. $\varrho$ Significantly more men $(86 \%)$ than women $\mathbb{D}$ (36\%) were either ex-smokers or current? smokers, and more men $(39 \%)$ than women (26\%) complained of a current cough. $\frac{O}{\mathbb{D}}$ Among ex-smokers and current smokers men $\stackrel{\circ}{\square}$ also had a higher mean (SD) pack year count $\cong$ $(49 \cdot 7(31 \cdot 6))$ than women $(29 \cdot 0(22 \cdot 8))$. No difference was found in history of tuberculo- 8 sis or general well being between the sexes. Current smokers tended to be younger (mean age 76.2$)$ than ex-smokers $(80.8)$ who were younger than never-smokers $(83 \cdot 6)$.

Figure 1 shows the proportion of residents with Heaf grade 3 or 4 by age of the individ- 


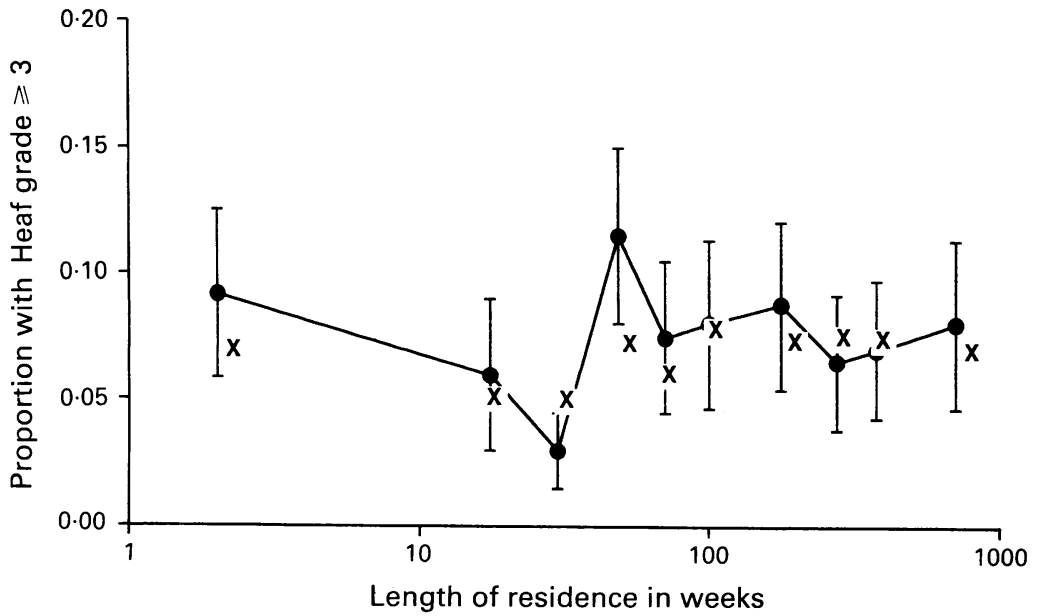

Figure 2 Relation between Heaf grade and length of residence in residential home. Residents were divided into 10 equal groups. The point on the horizontal axis represents the mean length of stay for each group. The $\mathrm{x}$ points on the graph represent Heaf grade proportion when adjusted for age. Vertical lines give $95 \%$ confidence intervals.

ual. Older people tended to have weaker Heaf grades, the odds ratio being 0.97 for each extra year, or 0.71 for each 10 year period.

The main purpose of the study was to determine whether tuberculin reactivity increased with length of stay. Figure 2 shows that tuberculin reactivity did not change with length of time in the home, whether or not potential compounding variables (such as age, smoking, or gender) were taken into acccount. The downward excursion at about 10 weeks' residence is seen to be factitious once age is accounted for ( $x$ points). A log scale has been used for the horizontal axis as the majority of patients had been in residence for under 150 weeks.

One unexpected finding of the study was that smoking appeared to be associated with increased Heaf grade reaction, with ex-smokers having an odds ratio of 1.20 and current smokers 1.59 compared with never smokers. Increased smoking, assessed in pack years,

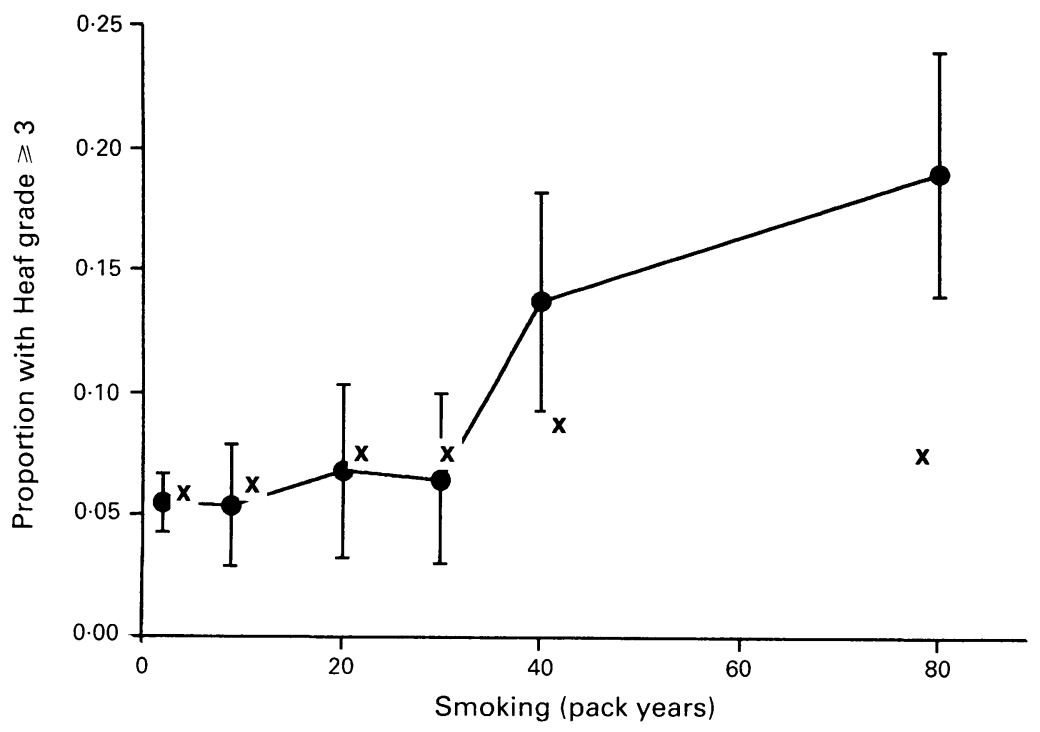

Figure 3 Relation between Heaf grade and smoking in pack years. Ex-smokers and current smokers were divided into six equal groups. Each point represents the mean age and the proportion with Heaf grade $\geqslant 3$ with $95 \%$ confidence intervals. The $\mathrm{x}$ points represent adjustment for age. was also associated with a stronger Heaf grade both in current smokers and ex-smokers (fig 3 ). After adjustment for age ( $x$ points) this association is less evident but still significant.

A second unexpected finding was that, once age and smoking were taken into account, the odds ratio for men being above any given cutoff point in Heaf grade was 1.62 (95\% confidence interval 1.32 to 1.99 ) compared with women. This implies that being male is associated with a stronger Heaf reaction.

In non-smokers the absence of cough and general well being showed no significant correlation with Heaf positivity. A weak correlation was found between cough and Heaf positivity for ex-smokers $(p<0.05)$ and a slightly stronger correlation for current smokers $(p<0.02)$. Only 48 residents were taking potentially immunosuppressive treatment and no significant difference in Heaf positivity was found between this group and the other residents.

\section{Discussion}

There are three principal findings from this tuberculin survey of the elderly in residential homes in Liverpool.

First, the incidence of tuberculin positivity declines with age. This is a well established phenomenon, consistent with a number of earlier studies, ${ }^{61617}$ and has been attributed to a decline in cellular immunity with age, ${ }^{18}$ eradication of the dormant infecting organism from within the host, or a combination of both. In this study $83.6 \%$ of the population were Heaf grade 0 or 1 . Other studies have shown that, although $10 \%$ of tuberculosis cases in the aged remain anergic, the remainder of the elderly population show no waning of tuberculin reactivity to mycobacterial infection with age. ${ }^{1920}$ It remains possible that Heaf test reactivity may be a useful guide to reinfection in the elderly when tracing contacts following an outbreak. The elderly, the vast majority of whom would be expected to be Heaf negative, may react to infection by tuberculin conversion in a way similar to children who have not been exposed to infection or received BCG immunisation. Our observation of reduced positivity with age supports other work ${ }^{61617}$ and is evidence of the reliability of methods used in this study.

Secondly, we have shown that there is no tendency for an increase in tuberculin reactivity with length of stay in residential homes, suggesting that residents in the homes are not at increased risk of tuberculosis infection. This finding is therefore at variance with the results of Stead et $a l^{4}$ in Arkansas, but not with other workers in San Francisco, ${ }^{21}$ although numbers in the latter study were small.

There are a number of possible reasons for this variance. First, the underlying incidence of disease in the elderly in the UK is lower than that in Arkansas. Stead et al cite rates of 50-100 per 100000 in the elderly in 
Arkansas, whereas in the UK the rates are about $10 / 100000$ in women and 25/100 000 in men. ${ }^{2}$ However, in Liverpool in the early 1980 s this figure was as high as $30 / 100000 .^{22}$ Secondly, nursing homes in Arkansas are, on average, nearly four times larger than those in this study (150 residents compared with 40). Thirdly, there may be more communal sleeping in the Arkansas homes. Few homes in the UK have more than two residents to a bedroom and most have individual bedrooms, although communal eating and dwelling rooms are used more extensively. The chances of cross infection in nursing homes in the UK may therefore be less. It is of interest that Stead et al showed increased tuberculin positivity with length of stay ${ }^{4}$; no statistical allowances were made for the likely decline in tuberculin reactivity with increasing age, a finding confirmed in a later paper. ${ }^{23} \mathrm{Had}$ such allowances been made, it is likely that residents would have shown an even larger proportion converting to a significantly positive test with length of stay.

The third finding from this study is that smokers have significantly stronger Heaf tests than ex-smokers who, in turn, have stronger tests than non-smokers. It has been shown that smoking increases the risk of tuberculosis. A recent study from Shanghai showed that the relative risk for tuberculosis in heavy smokers compared with non-smokers was 2.17 (95\% confidence interval 1.29 to $3 \cdot 63),{ }^{24}$ confirming what has been suggested in earlier studies. ${ }^{25} 26$ However, none of these studies has detailed the tuberculin status of smokers, whether or not tuberculosis was present. We believe this is the first time that such an observation has been made.

This finding supports the suggestion ${ }^{23}$ that the hypersensitivity reaction remains potentially active in most elderly people, and in our view it is maintained by smoking or reactivated by infection with the tubercle bacillus. This study has also shown that, allowing for the extra smoking and relative youth of men compared with women, the men had significantly stronger Heaf grades (odds ratio 1.62). It is well established that, in the latter half of life, men have a very much higher morbidity and mortality from tuberculosis. ${ }^{27}$ This finding further suggests that a strong Heaf reaction may be an indication of susceptibility rather than immunity to tuberculosis.

It is possible that the relation between smoking and tuberculin positivity may be a social class phenomenon. This was not investigated in this study.

Our findings show no increasing risk of tuberculosis infection with length of stay in the elderly living in residential homes in the UK, as appears to be the case in the US. Further studies in other centres in the UK may be required to establish this, and comparison with a matched population remaining in the community is needed. The tuberculin reaction, far from being of little importance in the elderly, may provide useful evidence of disease or infection when diagnostic assessment or contact tracing is being undertaken. Smoking may increase the risk of tuberculosis by damaging local not humoral borne immunity.

We would like to thank the British Lung Foundation for funding Dr Nisar and Evans Medical for their financial contribution. We thank Dr Agnew for helping to set up the project and for his helpful comments during its running, and Julie Hotchkiss for obtaining references. We also thank members of the Working Party of the Research Committee of the British Thoracic Society for their advice in drawing up the protocol and Miss Nicola Moon for typing the manuscript.

1 Medical Research Council Tuberculosis and Chest Disease Unit National Survey of Tuberculosis Notifications in England and Wales 1983. Characteristics of disease. Tubercle 1987;68:19-32.

2 Nisar M, Narula I, Beeching N, Davies PDO. HIV related tuberculosis in England and Wales. Tubercle Lung Dis 1992;73:200-2.

3 Central Statistical Office. Social trends. London: HMSO, 1992:22.

4 Stead WW, Lofgren JP, Warren E, Thomas C. $\vec{N}$ Tuberculosis as an endemic and nosocomial infection $G$ among the elderly in nursing homes. $N$ Engl $f$ Med 1985;312:1483-7.

5 Stead WW. Does the risk of tuberculosis increase in old age? I Infect Dis 1983;147:951-5.

6 Stead WW. Tuberculosis among elderly persons: an outbreak in a nursing home. Ann Intern Med 1981;94: 606-10.

7 King D, Davies PDO. Disseminated tuberculosis in the elderly: still a diagnosis overlooked. $\mathcal{F} R$ Soc Med 1992; 85:48-50.

8 Nisar M, Davies PDO. Current trends in tuberculosis mortality in England and Wales. Thorax 1991;46: 438-40.

9 Editorial. Tuberculosis and the alcoholic. Lancet 1978; ii:460-1.

10 Patel KR. Pulmonary tuberculosis in residents of lodging houses, night shelters and common hostles in Glasgow: a five year prospective survey. $\mathrm{Br} \mathcal{F}$ Dis Chest 1984 79:60-5.

11 Department of Health. Immunisation against infectious disease. London: HMSO, 1990:83-7.

12 McCullagh P. Regression models for ordinal data (with discussion). F $R$ Statistical Soc, Series B 1980;42:109-42.

13 Ashby D, West CR, Ames D. The ordered logistic regression model in psychiatry: rising prevalence of dementia in old peoples' homes. Stat Med 1989;8:1317-26.

14 SUG I supplemental library users' guide version 5. North Carolina: SAS Institute, 1986.

$15 S$ Plus for work statistics. Version 2.3. Oxford: Statistical Sciences, 1990

16 Johnston RN, Ritchie RT, Murray IHF. Declining tuber- 3 culin sensitivity with advancing age. $B M \mathcal{F}$ 1963;2: $720-4$.

17 Grzybowski S, Allen EA. The challenge of tuberculosis in decline: a study based on the epidemiology of tubercu- $\mathrm{O}$ losis in Ontario, Canada. Am Rev Respir Dis 1964; losis in 0 .

18 Saltzman RL, Peterson PK. Immunodeficiency in the elderly. Rev Infect Dis 1987;9:1127-35.

19 Battershill HJ. Cutaneous testing in the elderly patient $\mathrm{N}$ with tuberculosis. Chest 1980;77:188-9.

20 Politz LS, Aronsohn MH. Tuberculin sensitivity in the $N$ aged. Am Rev Tuberc Dis 1957;75:461-8.

21 Perez-Stable EJ, Flaherty D, Schecter G, Slutkin G, $\omega$ Hopewell PC. Conversion and reversion of tuberculin reactions in nursing home residents. Am Rev Respir Dis $C$ 1988;137:801-4.

22 Liverpool Health Authority public health annual report. 1988.

23 Stead WW, To T. The significance of the tuberculin skin $\square$ test in elderly persons. Ann Intern Med 1987;107: test in

24 Yu G, Hsieh C, Peng J. Risk factors associated with the prevalence of pulmonary tuberculosis among sanitary workers in Shanghai. Tubercle 1988;69:105-12

25 Adelstien AM, Rimington J. Smoking and pulmonary tuberculosis: an analysis based on a study of volunteers for mass miniature radiography. Tubercle 1967;48: for mass

26 Lowe CR. An association between smoking and respiratory tuberculosis. $B M \mathcal{F} 1956 ; 2: 1081-3$

27 Springett VH. An interpretation of statistical trends in tuberculosis. Lancet 1952;i:521-4. 